\title{
THE USE OF VARI, GLI, AND VIGREEN FORMULAS IN DETECTING VEGETATION IN AERIAL IMAGES
}

\author{
Lim Soon Eng $^{1 *}$, Rozita Ismail $^{1}$, Wahidah Hashim ${ }^{2}$, Aslina Baharum ${ }^{3}$ \\ ${ }^{1}$ College Of Computer Science and Information Technology, University Tenaga Nasional (UNITEN) \\ Putrajaya Campus, Jalan IKRAM-UNITEN 43000 Kajang, Selangor, Malaysia \\ ${ }^{2}$ Institute of Informatics and Computing in Energy, University Tenaga Nasional (UNITEN) \\ Putrajaya Campus, Jalan IKRAM-UNITEN 43000 Kajang, Selangor, Malaysia \\ ${ }^{3}$ Faculty of Computing and Informatics (FKI), University Malaysia Sabah (UMS), Jalan UMS \\ 88400 Kota Kinabalu, Sabah, Malaysia
}

(Received: December 2018 / Revised: May 2019 / Accepted: August 2019)

\begin{abstract}
Vegetation monitoring is a task that requires much time and human effort, but by using an unmanned aerial vehicle with a system that can store captured data digitally, the task can be more manageable and efficient. Past research has shown many formulas were developed by researchers to capture vegetation data in varying conditions and equipment. This paper discusses an experiment conducted to test three of those formulas using visible band data images. The formulas are the visible atmospherically resistant index, the green leaf index, and the visible atmospherically resistant indices green. The objective of this paper is to report and discuss our findings from experiments conducted using each formula as well as to compare the accuracy of these formulas.
\end{abstract}

Keywords: Green leaf index; Vegetation indices; Vegetation monitoring; Visible atmospherically resistant index

\section{INTRODUCTION}

Planting vegetation benefits every living being on earth (William et al., 2012; Pauline et al., 2013). According to the book The Benefits of Urban Vegetation, a survey found that green vegetation can directly affect human health by reducing stress, encouraging physical activity and improving the living environment (Pauline et al., 2013). Most importantly, it also helps reduce the environment temperatures of urban areas (William et al., 2012). However, vegetation can be a problem, too. For example, in Bakersfield, CA, a developer had planted 300 redwoods directly under power line cables. As a result, tree trimming caused challenges that may have reduced the benefits of having vegetation (William et al., 2012). Monitoring vegetation is another issue for some agencies. Research found that a power energy provider had spent and allocated around USD2 billion to USD10 billion per year on vegetation management in order to have proper maintenance at their facilities and provide reliable electricity delivery to consumers (Rancea, 2014). Meanwhile, according to a power provider in South Australia known as SA Power Network, they completed vegetation inspections using a four-wheel-drive vehicle to inspect every potential vegetation encroachment (Lewis, 2018). According to research conducted by de Ronde et al. (2007), the main requirement of vegetation monitoring is to do comparability studies on data between different years. Visible atmospherically resistant index

\footnotetext{
${ }^{*}$ Corresponding author's email: limsooneng@live.com.my, Tel. +6012-6440288
}

Permalink/DOI: https://dx.doi.org/10.14716/ijtech.v10i7.3275 
(VARI), green leaf index (GLI) and visible atmospherically resistant indices green (VIgreen) have been used to perform vegetation monitoring by just using visible band (RGB) data. We have conducted an experiment to study and understand the behavior of vegetation formulas on the aerial images captured by unmanned aerial vehicles of different environments. The motivation is to familiarize and determine the differences in the results between each formula, which can be used by utilities industries when verifying vegetation encroachment in power transmission corridors. The purpose of conducting this research is to find out the most suitable formula to perform postprocessing of the images captured using consumer drones to highlight vegetation objects from other objects. It can reduce the time taken to perform monitoring for encroachment and trimming of large areas of vegetation.

\section{REMOTE SENSING FOR VEGETATION MANAGEMENT}

\subsection{Monitoring}

Monitoring is defined as a collection and analysis of repeated observations or measurements to evaluate changes in conditions and progress toward meeting a management objective ( Carpenter et al., 1999). Monitoring methods are divided into two categories. The first category is the current management approach is able to achieve the objective. If the first category could not achieve the identified objectives, it will fall into the next category: an alternative management approach to ensure that the process be achievable.

\subsection{Monitoring Vegetation with Technology}

Work conducted by Li et al. (2010) highlighted the aerial remote sensing technique used to detect and classify vegetation by using an algorithm they developed. Light detection and ranging (LiDAR) sensors are able to support and provide a density of points to improve tree segmentation through their remote sensing techniques ( $\mathrm{Li}$ et al., 2010). Other research has tried using remote sensing with multispectral and thermal imaging sensors in order to gather vegetation information such as leaf area index (LAI) and an estimation of chlorophyll (Berni et al., 2009). However, according to Burgan and Hartford (1993), vegetation monitoring can also be done by using satellite data captured by the advanced very high resolution radiometer.

\subsection{Vegetation Index Formulas}

There were several formulas introduced by past researchers that identify vegetation information. Our research focused on three of them: VARI, GLI, and VIgreen. These three formulas were used due to their approaches used in vegetation monitoring and their use of RGB data only. Hence, the use of a drone with a consumer camera was enough for capturing images.

$$
V A R I=\frac{(\text { Green }- \text { Red })}{\text { Green }+ \text { Red }- \text { Blue }}
$$

Equation 1 is used to estimate the fraction of vegetation with a minimal sensitivity to atmospheric effects (Gitelson et al., 2002; Mokarram et al., 2015; Mokarram et al., 2016). The addition of blue-band data in Equation 1 is to minimize atmospheric effects (Schneider et al., 2008). It can estimate the fraction of vegetation with an error of less than ten percent (Gitelson et al., 2002; Mokarram et al., 2016). Additionally, Equation 1 can also detect changes due to biomass accumulation and is sensitive to the amount of chlorophyll in the leaves (Viña et al., 2004). Equation 1 can also be used to compute the fire potential index by using data from the moderate resolution imaging spectrometer, to monitor the LAI and any used tree visible general visibleband (RGB) (Mckinnon \& Hoff, 2017).

$$
\text { VIgreen }=\frac{\text { Green }- \text { Red }}{\text { Green }+ \text { Red }}
$$


Vegetation index green is also known as green-red vegetation index (Motohka et al., 2010) as well as visible atmospherically resistant indices Green (VIgreen) (Ahamed et al., 2011). However, this formula is originally found by Gitelson et al. ( 2002). Equation 2 is another vegetation index that uses RGB data to interpret ground cover and identify green vegetation, soil, water, or snow base on its value. By observing the changes in data over 10-30 days, this formula can detect phenological changes and forest degradation in tropical forests (Nagai et al., 2014). Muraoka et al. (2013) have done an experiment to prove that VIgreen values will change according to the season (2013).

$$
G L I=\frac{2 \text { Green }- \text { Red }- \text { Blue }}{2 \text { Green }+ \text { Red }+ \text { Blue }}
$$

Green Leaf Index (GLI) was originally created by (Louhaichi et al., 2001) to determine the grazing impact of wheat. If the value is negative it represents soil or something nonliving, and if the value is positive it is either green leaves or stems (Louhaichi et al., 2001). Since Equation 3 is sensitive to greenish leaf, it is best used to determine rice leaf chlorophyll (Yuliantika et al., 2016). In another attempt, an experiment ten vegetation indices formula to detect pine wilt disease on trees. They found that Equations 1 and 2 can detect infected trees earlier than other vegetation formulas (Kim et al., 2018). However, they also found that Equation 3 has better modeling than the others (Yuliantika et al., 2016).

\section{METHOD AND TOOLS}

To assess the performance of these formulas (VARI, VIGreen, GLI), we have conducted empirical work; each section below further describes the steps involved.

\subsection{Data Gathering}

Data were obtained by our sponsoring agency. Images used in our experiment were captured using a drone equipped with a consumer camera.

\subsection{Data Processing}

The software QGIS, a type of geographical information system (GIS), was used to process the images. QGIS is a tool to process and analyze images from remote sensing captured data (Raturi \& Bhatt, 2004; Mokarram et al., 2016). According to Gunawan et al. (2013), QGIS can support decision makers in preparing more accurate spatial maps and processing remote sensing data with less time and expense. First, the images are loaded into QGIS and the raster calculation function is used to insert the Equations 1,2, or 3. The final result will be a grayscale image to represent the value of the formula in each pixel. Figure 1 shows the original image and the grayscale image.

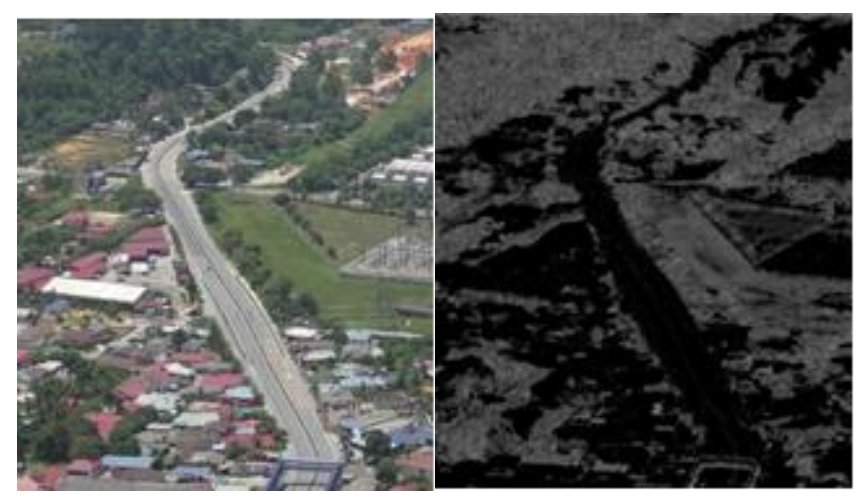

Figure 1 Left is an example of the original image, and the right picture is an example of grayscale image after using VARI. OUNITEN 
Once the image was loaded and processed using the chosen formula, observations and comparisons were conducted between the results from each vegetation formula. At this stage, we still require QGIS software to load the grayscale image and then convert it into a single-band pseudocolor image to identify the value difference of each pixel based on the chosen color map. In QGIS, there are three modes to classify the pixels data in each representative color class based on the value: continuous, equal interval, and quantile. We found that quantile mode clearly shows the differences in each area in the image. Quantile classification is used to classify the data and equally numbered value of data or pixel in each of the color class or group. Which mean each of the color class will have equal number of pixels. This method would not give an empty number of pixels in classes. In order to find the total number of pixels per class, Equation 4 is used in the software. In our work, we have set the total class to 35 .

$$
\text { Total Number Pixel Per Class = Total Pixel / Number of Class }
$$

The reason for selecting the quantile classification is that human eyes have difficulty differentiating between each value in a grayscale image, so this step is done to make the image clearer and pixel values easier to identify.

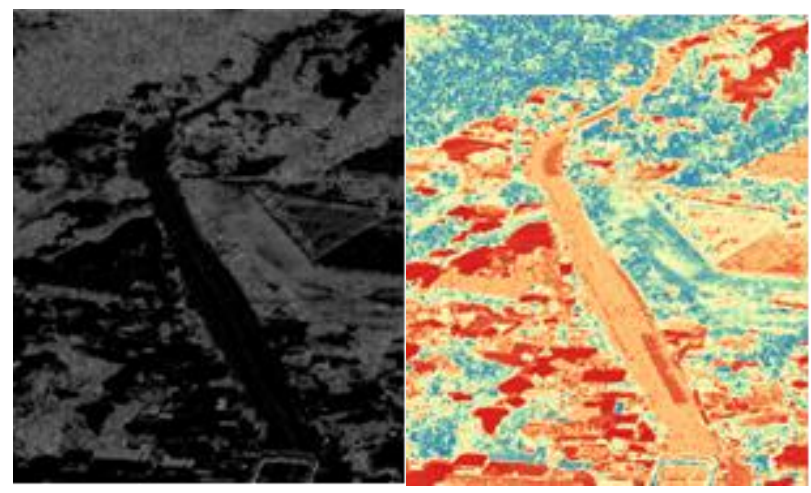

Figure 2 Left picture is a grayscale image and the right picture is the same image converted to a single-band pseudocolor image

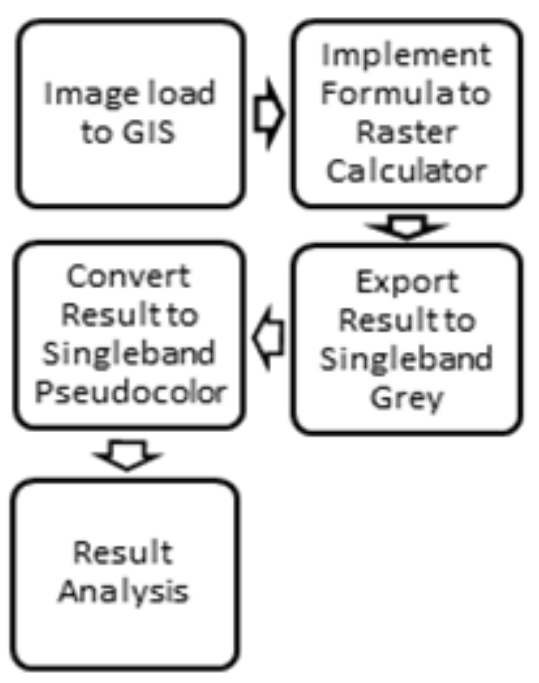

Figure 3 Flowchart of the steps in conducting the experiment

\subsection{Data Analysis}

Once each of the image data processes were completed, a comparison of the observation of singleband pseudocolor from different vegetation indices (VI) techniques was executed. During this 
phase, we were able to identify the differences between each of the VI techniques in the dataset and produce a final conclusion of the experiment. Figure 4 shows the process model in our empirical work.

\subsubsection{Error differences among VI}

The basic error difference calculation was adopted in order to analyze the gap differences among the selected VI techniques. The reason why this comparison is computed is to know the value differences among these techniques so that we can find the similarities between formulas.

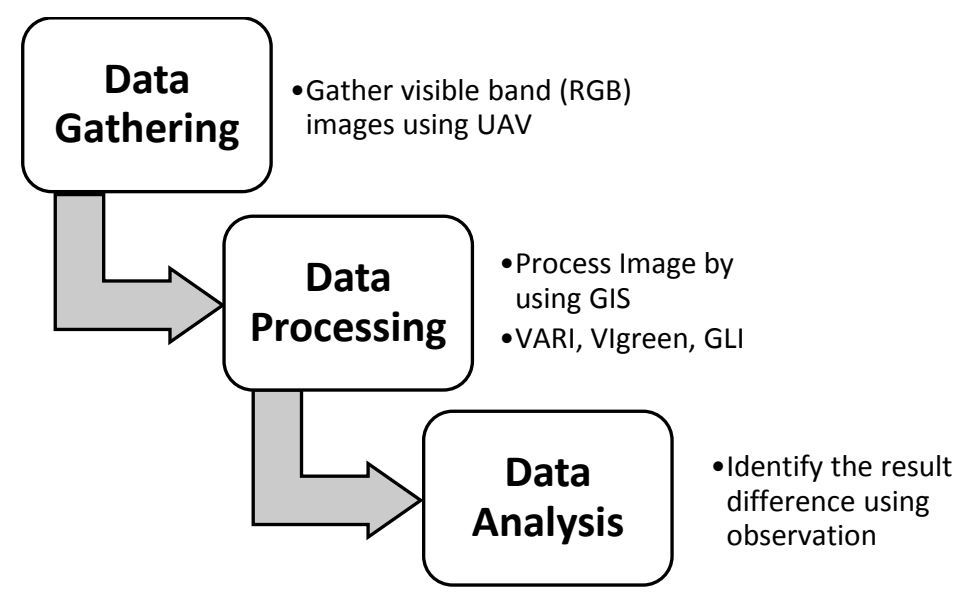

Figure 4 Process model for the proposed experiment

\section{RESULTS AND DISCUSSION}

After a batch of data were processed and analyzed, the results show few differences between the three vegetation formulas. In this section, we explain the differences among the selected formulas. First, the maximum and minimum values of the results were tabulated and compared. Using an image of our university campus categorized as an urban area picture, VARI shows significant differences as compared to VIGreen and GLI.

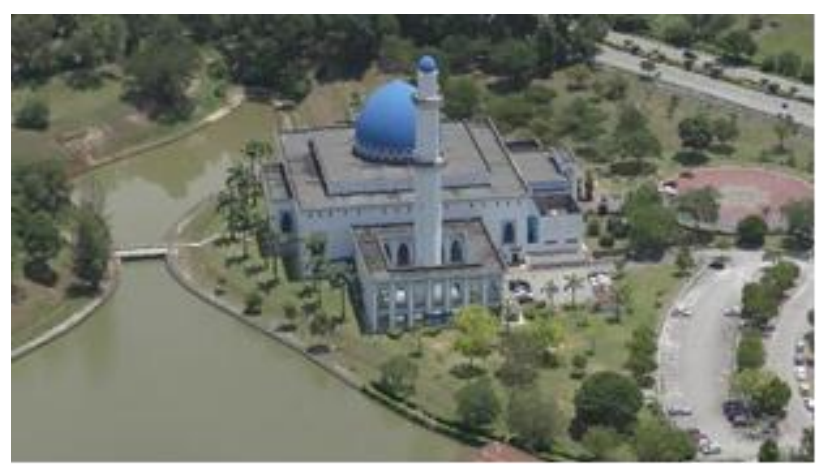

Figure 5 Original data with a mosque next to vegetation and non-vegetative objects at UNITEN campus. COUNITEN

Table 1 The result of the data from Figure 5

\begin{tabular}{lcc}
\hline \multicolumn{1}{c}{ Vegetation } & \multicolumn{2}{c}{ Result Data } \\
\cline { 2 - 3 } Index Formula & Minimum & Maximum \\
\hline VARI & -40 & 39.9 \\
VIgreen & -0.39 & 0.386 \\
GLI & -0.356 & 0.317 \\
\hline
\end{tabular}


Figure 5 is one of the sample data used in the experiment. According to the results listed in Table 1 , we can identify a huge value difference using the VARI formula. In contrast, the results of VIgreen and GLI are below 1 and above -1 . Next, we compared the differences between the formulas or indices after applied to the single-band pseudocolor.

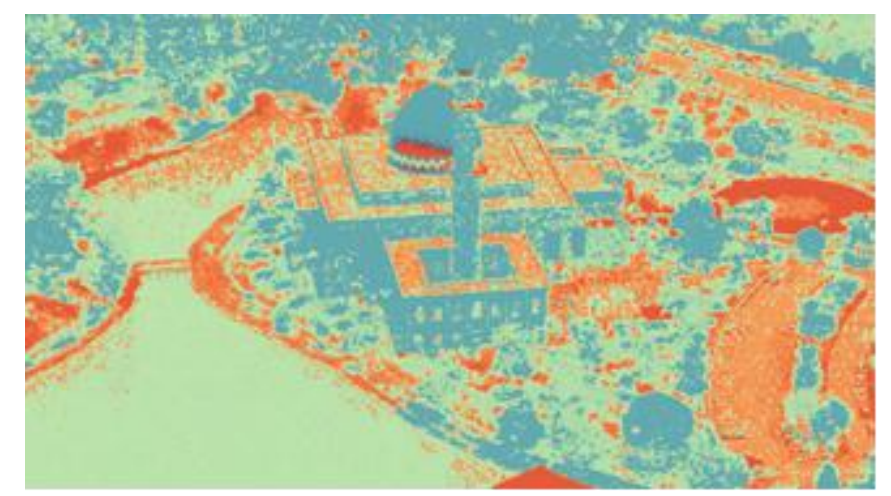

Figure 6 Converted singleband pseudocolor VARI result of Figure 5 data

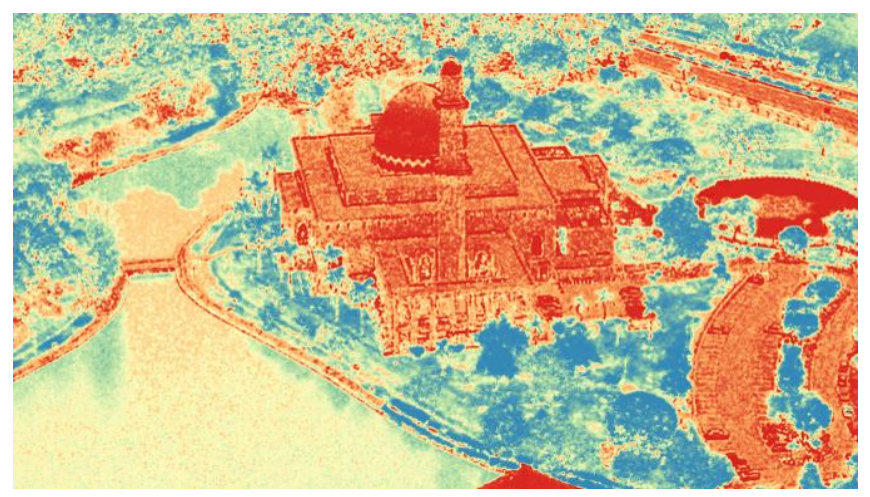

Figure 7 Converted singleband pseudocolor GLI result of Figure 5 data

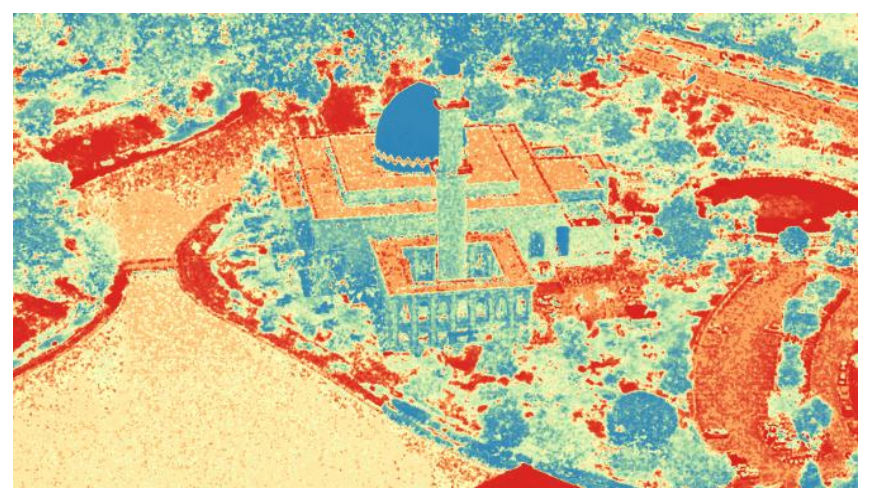

Figure 8 Converted singleband pseudocolor VIgreen result of Figure 5 data

Figure 6, Figure 7, and Figure 8 show images that have been converted to single-band pseudocolor. The areas in red indicate the negative or lower- than-median values of the image dataset; they are areas of non-vegetation. However, areas in green indicate positive or higherthan-median values of the image dataset; they are areas of vegetation. The results show some differences in terms of color, based on the formulas applied to the images. As an example, in Figure 6, we can clearly see most of the image is heavy green compared to Figure 7 and Figure 8, which use GLI and VIgreen. In the VARI and VIgreen results, the wall of the mosque is shown in green. In contrast, Figure 7, which uses GLI, shows most of the mosque building having the 
lowest value in the dataset. Another difference is in the color of the lake beside the mosque. Images using the VIgreen and GLI formulas show most of the lake below the dataset median, but some of the reflection makes the GLI image a light green color. Using the VARI formula results in most of the lake area being a positive green value, but the area of reflection is a negative red value.

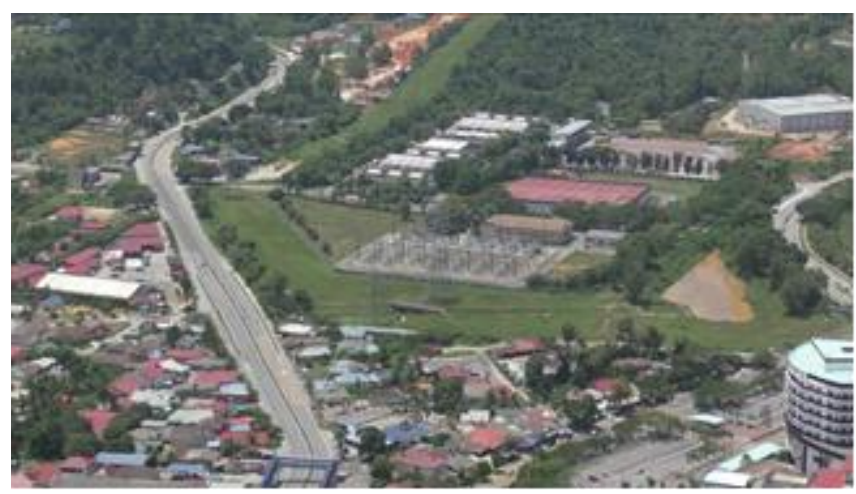

Figure 9 Original data that consists of houses and surrounding vegetation. OUNITEN

Table 2 The result of the data from figure 9

\begin{tabular}{lcc}
\hline \multicolumn{1}{c}{ Vegetation } & \multicolumn{2}{c}{ Result Data } \\
\cline { 2 - 3 } Index Formula & Minimum & Maximum \\
\hline VARI & -1.25 & 0.915 \\
VIgreen & -0.354 & 0.333 \\
GLI & -0.328 & 0.226 \\
\hline
\end{tabular}

Figure 9 is another example considered in the experiment. According to the above table, the ranges of the minimum and the maximum values of VIgreen and GLI are similar to each other. However, VARI still has the largest range in the results, though when compared to the previous table the range is smaller.

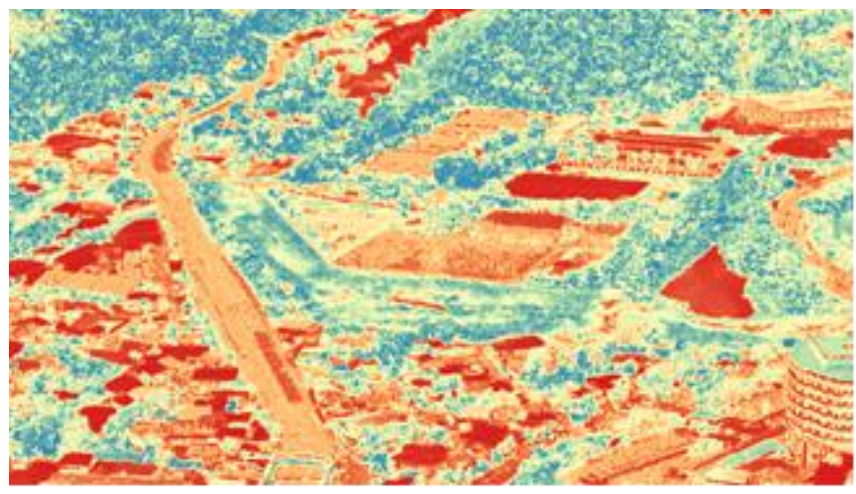

Figure 10 Converted singleband pseudocolor VARI result of Figure 9 data 


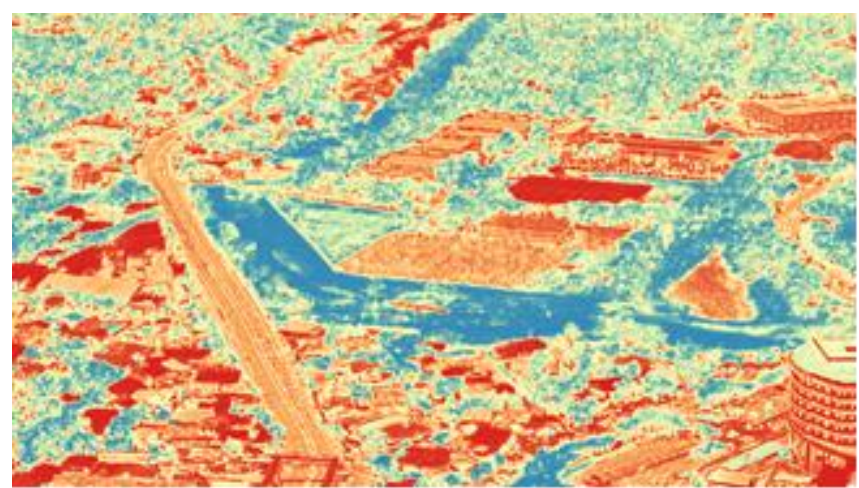

Figure 11 Converted singleband pseudocolor GLI result of Figure 9 data

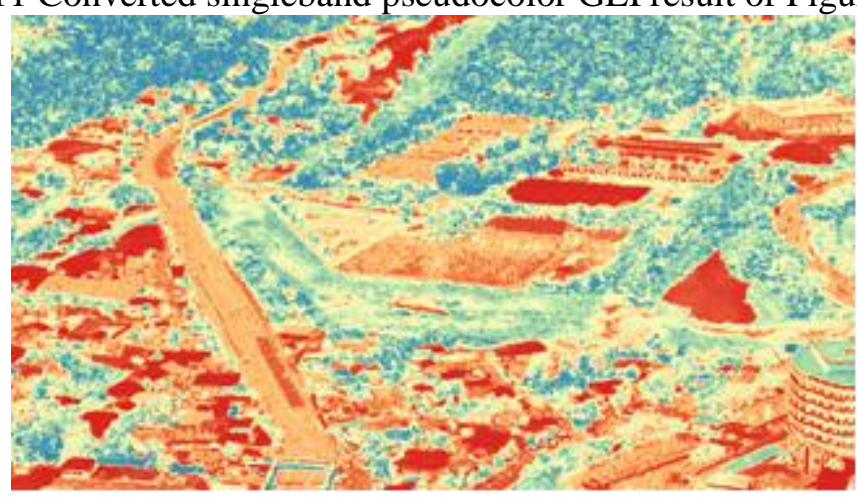

Figure 12 Converted singleband pseudocolor VIgreen result of Figure 9 data

Figure 10, Figure 11, and Figure 12 depict the single-band pseudocolor images the three formulas in our study were applied to. The green areas are the vegetation areas and the red areas are nonvegetation areas. Overall, the three results do not show any significant differences. However, the GLI output shows greater sensitivity to the green value in the middle part of the image compared to others. This clearly indicates that the value in the area is close to the maximum value of the whole dataset. The average value in the GLI vegetation is more positive than the other formulas' values. Similarly, while the GLI results show less general greenness in the forested area at the top of the image, individual trees and small amounts of non-tree area between each tree can be seen in more detail.

Table 3 The error differences comparison between each VI

\begin{tabular}{lc}
\hline \multicolumn{1}{c}{ Vegetation Indices } & Error Difference \\
\hline VARI - VIgreen & -0.0417 \\
\hline VARI - GLI & -0.0507 \\
\hline GLI - VIgreen & 0.0215 \\
\hline
\end{tabular}

In terms of the error differences shown in Table 3, GLI and VIgreen have the smallest value differences, which shows their similarity VI value between each of the on the selected image. VARI and VIgreen have significant differences as compared to the rest. By knowing such error value differences, we know the range that VARI uses is usually wider value in comparison with others formula used in this experiment. Hence, we have to be careful in using VARI \& VIgreen for detecting objects in urban areas. This is due to the fact that when there are many colors available in the image, the targeted objects can be mistaken for non-targeted objects. 


\section{CONCLUSION}

Throughout this experiment, it was found that the GLI formula proved the most suitable technique for highlighting vegetation in both urban areas and forest areas based on its sensitivity in detecting the differences between vegetation and non-vegetation. Overall, the three formulas can show green objects with minimal false detection in single-band pseudocolor. As for future work, we will include machine-learning techniques and deep-learning analysis in the data processing in order to enhance the vegetation detection to a minimal percentage of misinterpretation.

\section{ACKNOWLEDGEMENT}

This research was supported by UNITEN internal grant, project code J510050744. We acknowledge the use of facilities and equipment provided by Micro Multi Copter Aero Science \& Technology and Kembara Impian Technologies Sdn. Bhd. We would like to thank Tuan Hussin Daud. and Mr. Alan from Kembara Impian as well as Mr. Edison and Mr. Ken from Micro Multi Copter Aero Science \& Technology for providing us suggestions based on their expertise and experience throughout the research.

\section{REFERENCES}

Ahamed, T., Tian, L., Zhang, Y., Ting, K.C., 2011. A Review of Remote Sensing Methods for Biomass Feedstock Production. Biomass and Bioenergy, Volume 35(7), pp. 2455-2469

Berni, J.A.J., Zarco-Tejada, P.J., Suárez, L., González-Dugo, V., Fereres, E., 2009. Remote Sensing of Vegetation from UAV Platforms using Lightweight Multispectral and Thermal Imaging Sensors. Int. Arch. Photogramm. Remote Sens. Spatial Inform. Sci, Volume 38(6), pp. $1-6$

Burgan, R.E., Hartford, R.A., 1993. Monitoring Vegetation Greenness with Satellite Data. Gen. Tech. Rep. INT-GTR-297. Ogden, UT: U.S. Department of Agriculture, Forest Service, Intermountain Research Station

Carpenter, A.T., Elzinga, C.L., Salzer, D. W., Willoughby, J.W., 1999. Measuring and Monitoring Plant Populations. Journal of Range Management, Volume 52(5), pp. 544. $10.2307 / 4003786$

Gitelson, A.A., Kaufman, Y.J., Stark, R., Rundquist, D., 2002. Novel Algorithms for Remote Estimation of Vegetation Fraction. Remote Sensing of Environment, Volume 80(1), pp. 7687

Gunawan, G., Sutjiningsih, D., Soeryantono, H., Sulistioweni, W., 2013. Soil Erosion Estimation based on GIS and Remote Sensing for Supporting Integrated Water Resources Conservation Management. International Journal of Technology, Volume 4(2), pp. 147-156

De Ronde, R., Haveman, R., 2007. Problem in Vegetation Monitoring in Nature Management Practice: Two Case Studies. Annali Di Botanica, Volume VII, pp. 77-84

Kim, S.R., Lee, W.K., Lim, C.H., Kim, M., Kafatos, M.C., Lee, S.H., Lee, S.S., 2018. Hyperspectral Analysis of Pine Wilt Disease to Determine an Optimal Detection Index. Forests, Volume 9(3), pp. 1-12

Lewis, A., 2018. Networks Protocol for Vegetation Management Near Powerlines 2016-2018. Available Online at https://www.sapowernetworks.com.au/public/download.jsp?id=54955

Li, Z., Walker, R., Hayward, R., Mejias, L.. 2010. Advances in Vegetation Management for Power Line Corridor Monitoring using Aerial Remote Sensing Techniques. In: Proceedings of the First International Conference on Applied Robotics for the Power Industry (CARPI), pp. 1-6

Louhaichi, M., Borman, M.M., Johnson, D.E., 2001. Spatially Located Platform and Aerial Photography for Documentation of Grazing Impacts on Wheat. Geocarto International, Volume 16(1), pp. 65-70 
Mckinnon, T., Hoff, P., 2017. Comparing RGB-Based Vegetation Indices with NDVI for Drone Based Agricultural Sensing. Agribotix.Com, Volume 21(17), pp. 1-8

Mokarram, M., Boloorani, A.D., Hojati, M., 2016. Relationship between Land Cover and Vegetation Indices. Case Study: Eghlid Plain, Fars Province, Iran. European Journal of Geography, Volume 7(2), pp. 48-60

Mokarram, M., Hojjati, M., Roshan, G., Negahban, S., 2015. Modeling the Behavior of Vegetation Indices in the Salt Dome of Korsia in North-East of Darab, Fars, Iran. Modeling Earth Systems and Environment, Volume 1(27), pp. 1-9

Motohka, T., Nasahara, K.N., Oguma, H., Tsuchida, S., 2010. Applicability of Green-red Vegetation Index for Remote Sensing of Vegetation Phenology. Remote Sensing, Volume 2(10), pp. 2369-2387

Muraoka, H., Noda, H.M., Nagai, S., Motohka, T., Saitoh, T.M., Nasahara, K.N., Saigusa, N., 2013. Spectral Vegetation Indices as the Indicator of Canopy Photosynthetic Productivity in a Deciduous Broadleaf Forest. Journal of Plant Ecology, Volume 6(5), pp. 393-407

Nagai, S., Ishii, R., Suhaili, A. Bin Suhaili, Kobayashi, H., Matsuoka, M., Ichie., Motohka, T., Kendawang, J.J., Suzuki, R., 2014. Usability of Noise-free Daily Satellite-observed Greenred Vegetation Index Values for Monitoring Ecosystem Changes in Borneo. International Journal of Remote Sensing, Volume 35(23), pp. 7910-7926

Pauline, L., Damien, P., François, C., Julien S., 2013. The Benefits of Urban Vegetation. Plante $\&$ Cite

Rancea, G.V., 2014. Evaluation of Methods for Control of Vegetation in Utility Corridors. The University of San Francisco. Available Online at https://repository.usfca.edu/capstone/9

Raturi, G.P., Bhatt, A.B., 2004. Vegetation Pattern Analysis in Rudraprayag District using Remote Sensing and GIS. Journal of the Indian Society of Remote Sensing, Volume 32(2), pp. 217-224

Schneider, P., Roberts, D.A., Kyriakidis, P.C., 2008. A VARI-based Relative Greenness from MODIS Data for Computing the Fire Potential Index. Remote Sensing of Environment, Volume 112(3), pp. 1151-1167

Viña, A., Gitelson, A.A., Rundquist, D.C., Keydan, G., Leavitt, B., Schepers, J., 2004. Monitoring Maize ( L.) Phenology with Remote Sensing. Agronomy Journal, Volume 96(4), pp. 1139-1147

William, B., Most, B., Weissman, S., 2012. Trees and Power Lines: Minimizing Conflicts between Electric Power Infrastructure and the Urban Forest. City Streets, Berkeley Law. Available Online https://www.law.berkeley.edu/files/Trees_and_Power_Lines_March_2012.pdf

Yuliantika, G., Suprayogi, A., Sukmono, A., 2016. Analisis Pengunaan Saluran Visible untuk Estimasi Kandungan Klorofil Daun Pade dengan Citra Hymap. (Studi Kasus: Kabupaten Karawang, Jawa Barat). Jurnal Geodesi Undip, Volume 5(2), pp. 200-207 